\title{
Effect of Pyrolysis Temperature on the Electrical Behavior of Polymer-Derived SiOCN Ceramic
}

\author{
Yan Li1, Yuxi Yu1 ${ }^{*}$, Haisheng San ${ }^{1}$, Qingkai Han ${ }^{2}$, Linan An ${ }^{3}$ \\ ${ }^{1}$ Fujian Key Laboratory of Advanced Materials, Department of Materials Science and Engineering, College of \\ Materials, Xiamen University, Xiamen, China \\ ${ }^{2}$ School of Mechanical Engineering, Dalian University of Technology, Dalian, China \\ ${ }^{3}$ Department of Materials Science and Engineering, Advanced Materials Processing and Analysis Center, \\ University of Central Florida, Orlando, USA \\ Email: *yu heart@xmu.edu.cn
}

Received 23 August 2015; accepted 26 October 2015; published 29 October 2015

Copyright (C) 2015 by authors and Scientific Research Publishing Inc.

This work is licensed under the Creative Commons Attribution International License (CC BY).

http://creativecommons.org/licenses/by/4.0/

(c) (i) Open Access

\begin{abstract}
The conductivity of polymer-derived SiOCN ceramics exhibited an Arrhenius dependence on pyrolysis temperature, with the activation energy of $\sim 3.95 \mathrm{eV}$. The formation and structure change of the free carbon phase were detected by means of electron spin resonance spectroscopy and $X$-ray photoelectron spectroscopy. It reveals that the number of dangling bonds on the free carbon is increased as pyrolysis temperature increases, with the activation energy of $\sim 3.87 \mathrm{eV}$. So it is demonstrated that the pyrolysis-temperature induced increase in the conductivity is mainly attributed to the increase of dangling on the graphite-like carbon.
\end{abstract}

\section{Keywords}

Polymer Derived SiOCN Ceremic, Free Carbon, Activation Energy

\section{Introduction}

Polymer-derived SiOCN ceramics (PDC-SiOCN), synthesized by thermal decomposition of polymeric precursors, exhibited a set of superb physical and chemical properties, such as excellent high-temperature stability [1]-[3], oxidation/corrosion resistance [4] [5], creep resistance [6] [7], high-temperature semiconducting behavior [8] and high piezoresistivity [9]-[12]. Due to crying for the high-temperature stable sensor and component,

${ }^{*}$ Corresponding author.

How to cite this paper: Li, Y., Yu, Y.X., San, H.S., Han, Q.K. and An, L.N. (2015) Effect of Pyrolysis Temperature on the Electrical Behavior of Polymer-Derived SiOCN Ceramic. Journal of Materials Science and Chemical Engineering, 3, 9-16.

http://dx.doi.org/10.4236/msce.2015.310002 
electronic behavior of PDC has attracted tremendous interest in the past decades. Previous studies revealed that the structure of PDC-SiOCN is consisted of an amorphous matrix made of $\mathrm{SiC}_{\mathrm{x}} \mathrm{N}_{\mathrm{y}} \mathrm{O}_{4-\mathrm{x}-\mathrm{y}}(\mathrm{x}, \mathrm{y}$ are integers from 0 to 4) tetrahedra and nanosized carbon clusters (named free carbon), and the conduction mechanism of PDCSiOCN is attributed to the concentration and/or morphology of the free-carbon phase, which has higher conductivity than the amorphous SiOCN phase [13] [14]. When the carbon cluster concentration is higher than a critical value, the conduction of the materials is controlled by a tunneling-percolation mechanism, resulting in high piezoresistivity [9]-[12]. On the other hand, when the carbon cluster concentration is lower than the threshold value, the conduction of the materials is controlled by the matrix phase, leading to amorphous semiconducting behavior. Such amorphous semiconducting behavior has been widely reported by many researchers when the pyrolysis temperature is in the range of $1000^{\circ} \mathrm{C}$ to $1400^{\circ} \mathrm{C}$.

Despite of the extensive efforts, one phenomenon about the conduction of PDC-SiOCN ceramics has not been well understood. Although the matrix phase kept almost same in constitution and chemical bonding environment for the PDC-SiOCN ceramics with low free carbon concentrations, the conductivity of PDC-SiOCN ceramics can increase by 3 - 4 orders of magnitude with increasing pyrolysis temperatures [15] [16].

In this paper, we report the effect of pyrolysis temperature on the electrical behavior of PDC-SiOCN ceramics by measuring the conductivity properties, which is revealed that the room-temperature conductivity of the material exhibits an Arrhenius dependence on pyrolysis temperature. The activation energy of the Arrhenius dependence is similar to that for the increment of dangling bond concentration within free carbon. As a result, we deduce that the increase in the conductivity of the PDC-SiOCN ceramics is due to the increase in the conductivity of dangling bond concentration within free carbon.

\section{Experimental}

The PDC-SiOCN ceramics studied here are synthesized by thermal decomposition of a lab-made liquid phase polyvinylsilazane (PVSZ), which can be converted to SiOCN ceramics with 70 wt\% yield [17]. The liquid PVSZ was solidified by using $0.5 \mathrm{wt} \%$ of dicumyl peroxide as thermal initiator and subsequent thermal treatment at $140^{\circ} \mathrm{C}$ for $5 \mathrm{~h}$ in nitrogen. The obtained solid was crushed into fine powder of $\sim 1 \mu \mathrm{m}$ using high-energy ball milling, and then compressed into discs of $13 \mathrm{~mm}$ diameter and $1.5 \mathrm{~mm}$ thickness with the uniaxial pressing at $16 \mathrm{MPa}$ at room temperature. The discs are then pyrolyzed in a tube furnace under flowing of ultrahigh purity nitrogen (99.999\%) to convert them into fully dense SiOCN ceramics. Five kinds of samples are prepared by using different pyrolysis temperatures of $1000^{\circ} \mathrm{C}, 1050^{\circ} \mathrm{C}, 1100^{\circ} \mathrm{C}, 1150^{\circ} \mathrm{C}, 1200^{\circ} \mathrm{C}$ for $4 \mathrm{~h}$. The resultant samples are first identified by X-ray diffraction, which exhibits that all samples are amorphous without any diffraction peaks.

All the samples for electric experiment were polished firstly. Silver paste was then painted on the surfaces of the samples and annealed in air at $200^{\circ} \mathrm{C}$ for $1 \mathrm{~h}$ to form the electrodes. After that, the conductivities were measured at room temperature by measuring their current-voltage (I-V) curves (Keithley 4200, Keithley Instruments, Inc., Cleveland, $\mathrm{OH}$ ). To characterize the radical concentration, electron paramagnetic resonance (EPR) spectra of the samples are obtained using an X Band Bruker EMX spectrometer operating at $9.6 \mathrm{GHz}$ at room temperature. The EPR spectra are processed with Bruker WIN-EPR software. All the mass for EPR is $7 \mathrm{mg}$.

\section{Results and Discussion}

The conductivities of the PDC-SiOCN samples pyrolyzed at different temperatures were shown in Table 1, it ranges from $10^{-10}$ to $10^{-8} \mathrm{~S} / \mathrm{cm}$, and increases by 2 orders of magnitude. The relationship of the conductivities of PDC-SiOCN ceramics and their pyrolysis temperature was plotted as the natural logarithm of conductivity (Ln $(\sigma)$ ) against the reciprocal of temperature (1/T) (Figure 1). It is interesting to see that the conductivity exhibits Arrhenius dependence with respect to the pyrolysis temperature, similar as $\mathrm{SiC}(\mathrm{O})$ reported previously [18]. The apparent activation energy calculated from the curve in Figure 1 is $3.95 \mathrm{eV}$, which is higher than that reported previously for $\mathrm{SiC}(\mathrm{O})$ ceramics [18], which is arise from the $s p^{3}-s p^{2}$ transition in amorphous carbon with the value of the activation energy, ranging from 3.3 to $3.6 \mathrm{eV}$ [19] [20], so there should be another impact factor account for the change of the conductivity.

To understand the phenomenon above, the dangling bonds within the materials were studied using EPR. Figure 2 shows the room-temperature EPR spectrum of the PDC-SiOCN ceramics obtained at $1000^{\circ} \mathrm{C}$ to $1200^{\circ} \mathrm{C}$. All observed species occur in a range of $g$-values of $2.0012 \pm 0.0002$. The small values deviation of the $g$ values from the free-electron-spin $g$ value suggest that the observed spins originate from carbon-inherited spin species 


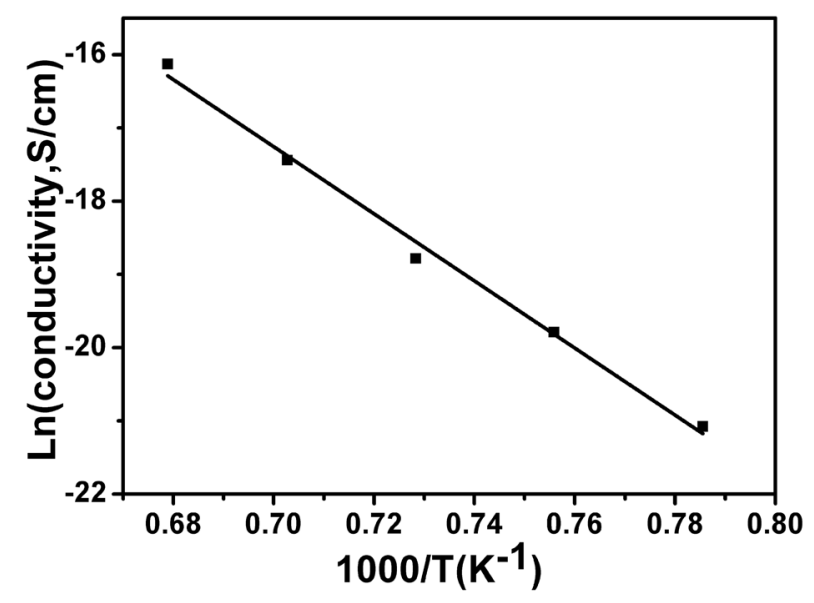

Figure 1. Conductivity of PDC-SiOCN as a function of pyrolysis temperature in an Arrhenius plot.

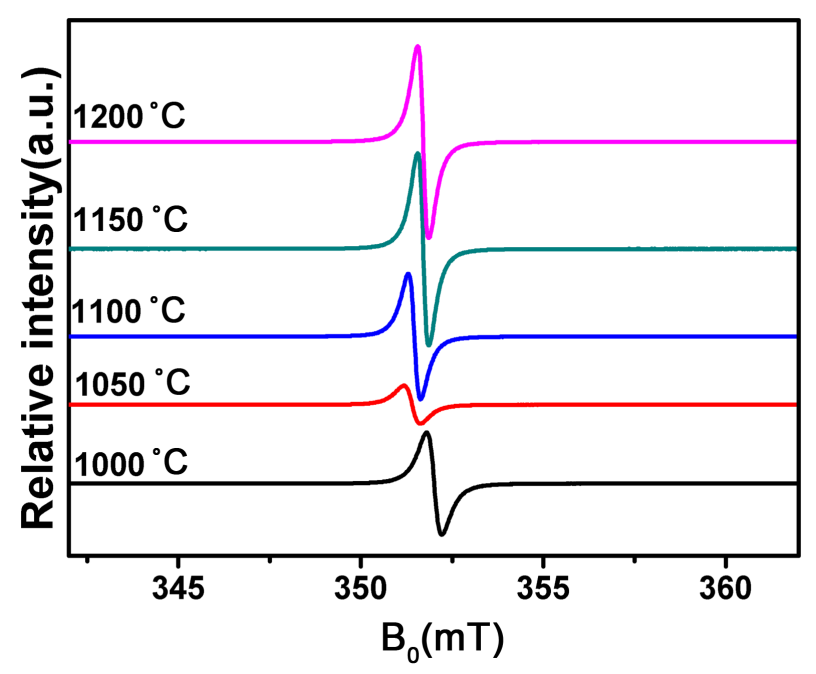

Figure 2. Room temperature EPR spectra of PDC-SiOCN samples pyrolyzed at different temperatures.

Table 1. Conductivity of the PDC-SiOCN ceramics pyrolyzed at different temperatures.

\begin{tabular}{cccccc}
\hline Pyrolysis Temperature $\left({ }^{\circ} \mathrm{C}\right)$ & 1000 & 1050 & 1100 & 1150 & 1200 \\
\hline Conductivity $(\mathrm{S} / \mathrm{cm})$ & $7.02 \times 10^{-10}$ & $2.46 \times 10^{-9}$ & $6.96 \times 10^{-9}$ & $2.65 \times 10^{-8}$ & $9.93 \times 10^{-8}$ \\
\hline
\end{tabular}

in the graphite nanoparticles, in accordance with the results previously obtained for similar materials [21]-[24].

In order to abstract the structural information, the EPR spectra in Figure 2 were further studied. Intensity ( $I$ ) and linewidth $\left(\Delta H_{p p}\right)$ were estimated by relative peak to peak height in the derivative resonance curves. The number of spins $(N)$ was roughly calculated by [25]:

$$
N=I\left(\Delta H_{p p}\right)^{2}
$$

Figure 3 plots the $\Delta H_{p p}$ and $N$ of the graphite like carbon as a function of pyrolysis temperature. In Figure 3(a), the line width is different according with the annealing temperature. It means that different hybridization states are distinguished. The $s p^{2}$-hybridization is characterized by line widths larger than 10 Gauss and $s p^{3}$-hybridization by values below 10 Gauss, due to the different extents of spin delocalization within the "in-plane" 


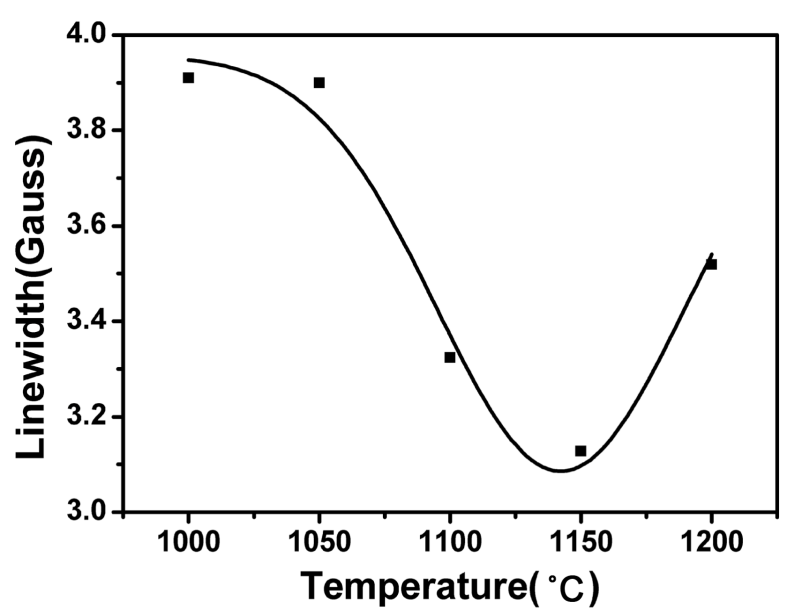

(a)

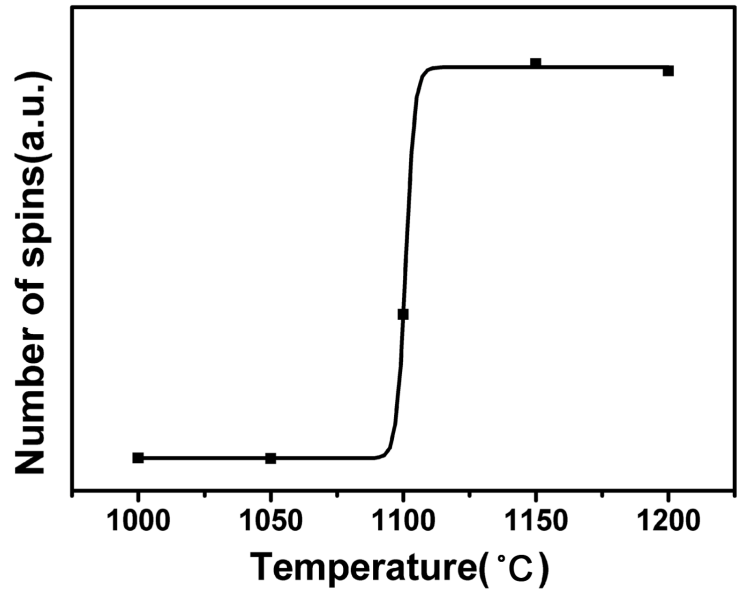

(b)

Figure 3. $\triangle \mathrm{Hpp}(\mathrm{a})$ and $\mathrm{N}(\mathrm{b})$ for PDC-SiOCN samples as a function of pyrolysis temperature.

dangling bonds. All samples contain $s p^{3}$-type carbon dangling bonds. But it is interesting that a critical temperature range between $1150^{\circ} \mathrm{C}$ and $1200^{\circ} \mathrm{C}$ is observed: below this, the peak to peak linewidths decrease with increasing pyrolysis temperature, while above it, the peak to peak linewidths increase with increasing pyrolysis temperature. The similar phenomenon but inverse tendency was emerged in the exploration of the number of spins. The number of spins increases up to $1150^{\circ} \mathrm{C}$, then remains constant as shown in Figure 3(b).

According to Ferrari and co-workers, [18] the activation energy of the graphitization of amorphous carbon can be calculated using following equation:

$$
E=K T_{c} \ln (v \tau)
$$

where $K$ is Boltzmann constant, $v$ is the phonon frequency of carbon which is $\sim 5 \times 10^{13}, \tau$ is a constant about $\sim 1$ $\mathrm{s}$, and $T_{c}$ is a characteristic temperature where the structure of the amorphous carbon exhibits a sudden change. According to the result from EPR, we select $1150^{\circ} \mathrm{C}$ as the characteristic temperature for the current material. The activation energy for the increasing of C-spins concentration in the PDC-SiOCN ceramics was thereby calculated to be $\sim 3.87 \mathrm{eV}$. This value is very close to that measured for the conduction change, suggesting that the increase in the conductivity of the PDC-SiOCN ceramics with pyrolysis temperature is likely due to the increase in carbon conductivity caused by the $C$-dangling bond creation.

In order to identify the chemical bonds of $\mathrm{C}$, the XPS spectral about $\mathrm{C}_{1 s}$ were obtained. The typical $\mathrm{C}_{1 s}$ energies spectra were shown in Figure 4, the numerical fitting was carried out and the peaks attributed were decomposed into four deposition conditions which are listed in Table 2. The 283.5, 284.7, 285.3, and 287.0 eV can be assigned to $\mathrm{C}-\mathrm{Si}, \mathrm{Csp}^{2}, \mathrm{Csp}^{3}$, and $\mathrm{C}=\mathrm{O}$, respectively. It can seen that the composition of free carbon is decreased slightly with the increasing annealing temperature. Although the composition of $\mathrm{C}=\mathrm{O}$ is decreasing with the increasing annealing temperature, it is higher than the similar SiCN(O) ceramic in particular [26], which may be the reason for the higher activation energy.

The absorption spectra (Figure 5) were used to obtain the information about the electronic structures of the PDC-SiOCN ceramics. All samples have a strong absorption in ultraviolet and visible regions.

The transition from localized defect energy to the delocalized states can be obtained from the optical absorption spectra at a lower excitation by using the equation [27] [28]:

$$
\alpha h v=B\left[h v-\left(E_{C}-E_{d}\right)\right]^{n}
$$

where $\alpha$ is the absorbance of amorphous materials, B is a constant, the $n$ is an index which can assume values of $1,2,3,1 / 2$ and $3 / 2$ depending on the nature of the interband electronic transitions, $E_{c}$ is the edge of the extended conduction band and $E_{d}$ is a deep defect level with a density of state. It can be seen that the spectra (Figure 6(a)) with in range of $0.55-1.3 \mathrm{eV}$ are well fitted by Equation (3) and the values of the $n, E_{c}-E_{d}$ were listed in Table 3. The optical gap $\left(E_{g}\right)$ for a direct transition in some amorphous semiconductors can be gotten using the equation at a higher energy range (3.5 - $5.5 \mathrm{eV})$ [29]: 


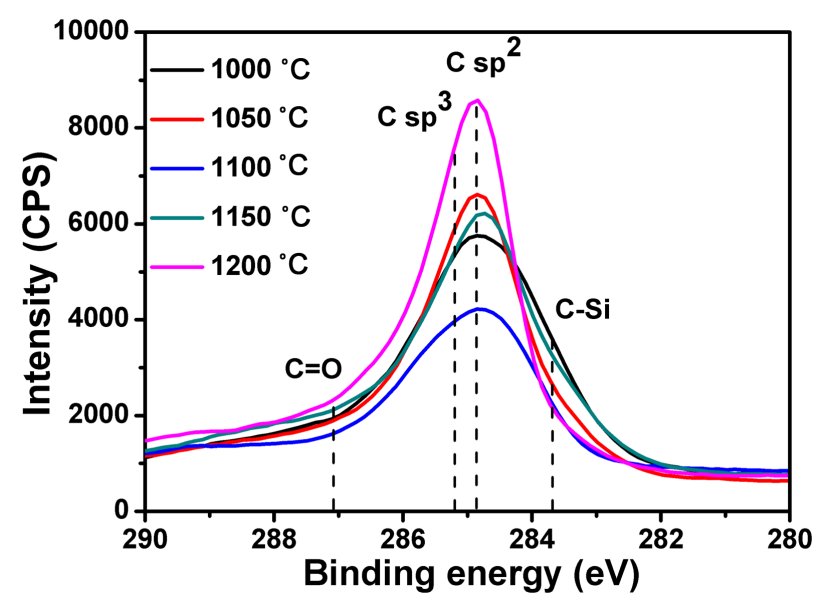

Figure 4. XPS spectra for C $1 \mathrm{~s}$ of PDC-SiOCN ceramics prepared at different temperature.

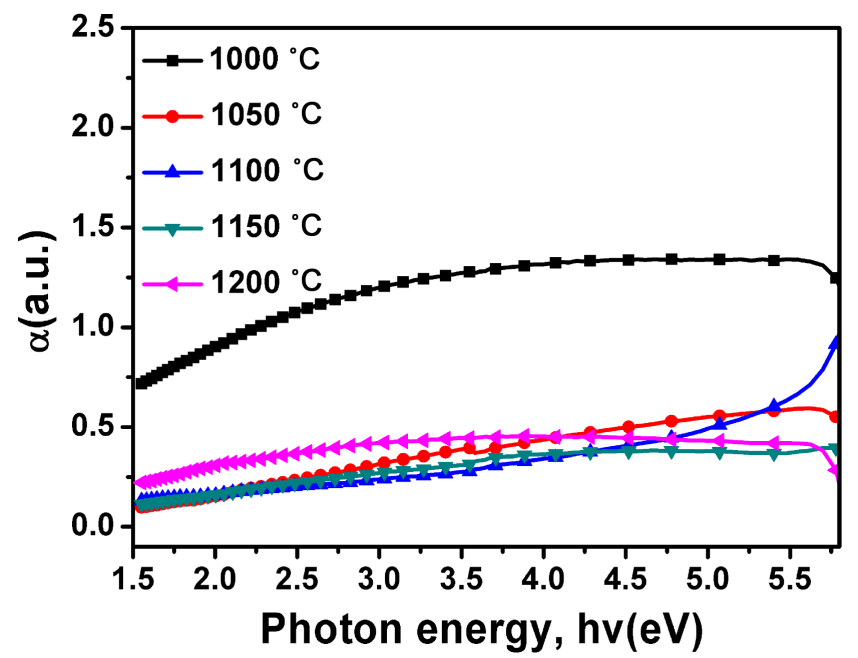

Figure 5. Dependence of room temperature absorption coefficient $\alpha$ on the photon energy for PDC-SiOCN pyrolyzed at different temperatures.

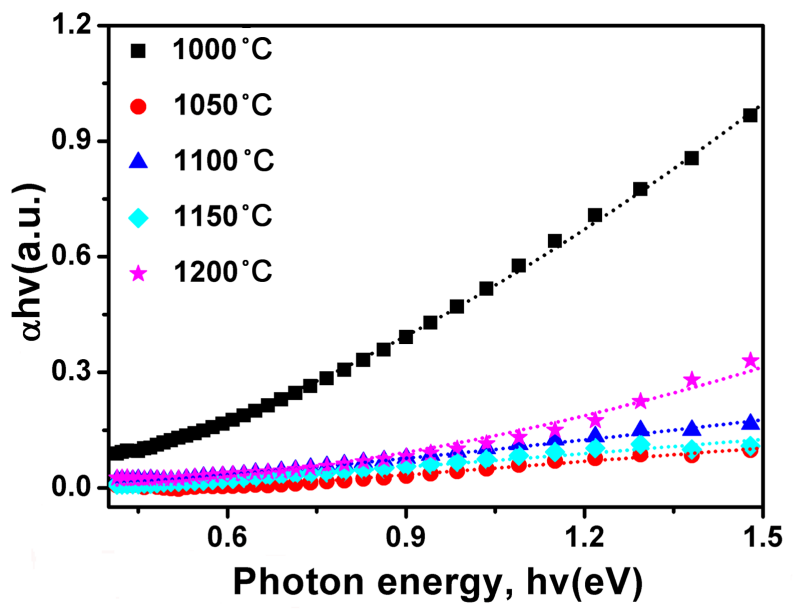

(a)

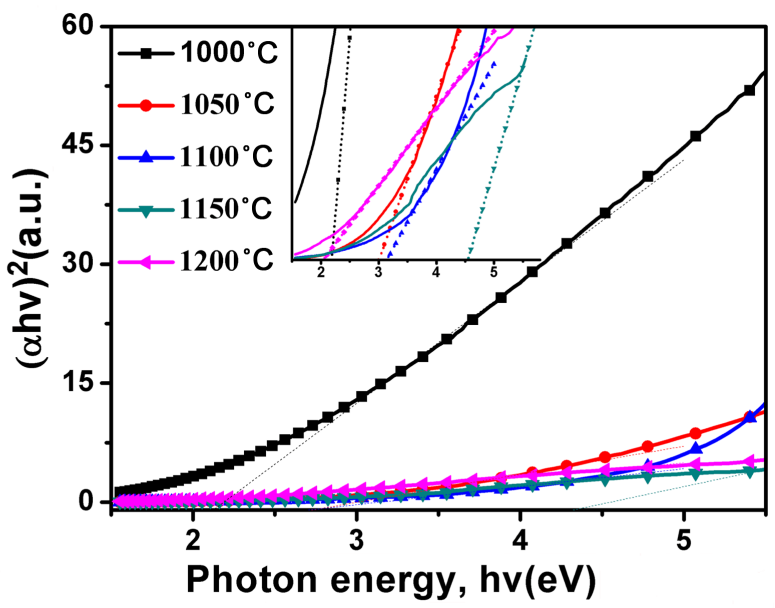

(b)

Figure 6. Plots of $\alpha h v$ (a) and $(\alpha h v)^{2}$ as a function of the photon energy for the PDC-SiOCN ceramics prepared at different temperature. The solid lines are experiment data; the dot lines are curve fits using Equation (3) (a) and Equation (4) (b). 
Table 2. Binding energy positions and relative fractions (\%) of the binding types attributing to XPS C $1 \mathrm{~s}$ spectra of PDCSiOCN ceramics pyrolyzed at different temperatures.

\begin{tabular}{|c|c|c|c|c|c|}
\hline Temperature $\left({ }^{\circ} \mathrm{C}\right)$ & $\begin{array}{c}\text { C-Si } \\
283.5(\mathrm{eV})\end{array}$ & $\begin{array}{c}C s^{2} \\
284.7(\mathrm{eV})\end{array}$ & $\begin{array}{c}C s p^{3} \\
285.3(\mathrm{eV})\end{array}$ & $\begin{array}{c}\mathrm{C}=\mathrm{O} \\
287.0(\mathrm{eV})\end{array}$ & $\mathrm{C} s p^{2} \& \mathrm{C} s p^{3}$ \\
\hline 1000 & 14.20 & 25.68 & 40.46 & 19.66 & 66.14 \\
\hline 1050 & 15.45 & 27.74 & 40.12 & 16.61 & 67.86 \\
\hline 1100 & 26.32 & 36.07 & 21.32 & 16.22 & 57.39 \\
\hline 1150 & 33.50 & 31.31 & 21.09 & 14.11 & 52.40 \\
\hline 1200 & 37.68 & 31.11 & 21.30 & 9.93 & 52.41 \\
\hline
\end{tabular}

Table 3. Curve Fit Parameters for PDC-SiOCN ceramics pyrolyzed at different temperatures.

\begin{tabular}{cccc}
\hline Temperature $\left({ }^{\circ} \mathrm{C}\right)$ & $\mathrm{n}$ & $E_{c}-\mathrm{E}_{\mathrm{d}}(\mathrm{eV})$ & $E_{g}(\mathrm{eV})$ \\
\hline 1000 & 1.58 & 0.15 & 2.34 \\
1050 & 1.34 & 0.53 & 3.01 \\
1100 & 1.26 & 0.26 & 3.14 \\
1150 & 1.24 & 0.28 & 4.54 \\
1200 & 1.90 & 0.23 & 2.04 \\
\hline
\end{tabular}

$$
(\alpha h v)^{2} \propto\left(h v-E_{g}\right)
$$

The band gap is defined as the energy at which the straight line extrapolated from the straight part of the plot intersects the horizontal (energy) axis. The band gaps obtained for the samples were listed in the Table 3 , too. The band gap is decreasing with the increasing pyrolysis temperature.

Now, we would like to correlate the change in the conductivity of the point defects affecting the overall conductivity of a PDC with a low free-carbon concentration where no percolation (or tunneling-percolation) is formed. At temperature above $1000^{\circ} \mathrm{C}$, amorphous SiOCN ceramics is obtained as the conductive phase of carbon and the semiconductive phase

SiOCN matrix. The precipitations of carbon occurs resulting in regions with $\mathrm{C}-\mathrm{C}$ bonds, along with the release of ammonia and hydrogen, so many dandling on free carbon $\mathrm{sp}^{3}$ hybridization were leaved in the SiOCN material. The C-dangling bonds works as donor defects to give electrons and to form defect states within the band gap. The number of the dandling is increased with the increasing annealing temperature, which could lead to an increase in the density of the defect states, resulting in the Fermi level moving toward the conduction band and band tail, so the gap between the edge of the extended conduction band and a deep defect level with a density of state $\left(E_{c}-E_{d}\right)$ decreases with increasing pyrolysis temperature as shown in Figure 7, correspondingly, the conductivity of the PDC-SiOCN is increasing with the elevated temperature [28].

\section{Summary}

In this paper, PDC-SiOCN ceramics were produced via thermal decomposition of a liquid-phased PVSZ. The effect of pyrolysis temperature on the conductivity of a low free carbon amorphous PDC-SiOCN ceramics was first studied. It was found that the conductivity of the material increased by 2 orders of magnitude when pyrolysis temperature increased from $1000^{\circ} \mathrm{C}$ to $1200^{\circ} \mathrm{C}$, and the conductivity exhibited Arrhenius dependence on the pyrolysis temperature. The "apparent” activation energy was calculated from the Arrhenius plot to be $3.95 \mathrm{eV}$. The microstructure of the materials was then characterized by using EPR and XPS. We find that the spin concentration on carbon cluster increases at elevated temperature, along with the slight decreasing of carbon cluster. The activation energy is similar with the result calculated from the Arrhenius. Thereafter, the electronic structure was obtained by using the optical absorption spectra. It is found that the gap between the deep defect states and the mobility edge is decreased with the increasing pyrolysis temperature, which is due to the increasing of the dangling on the carbon, and then make the gap between the Fermi level and the conduction band decreases with increasing pyrolysis temperature. We, thereby, believe that the increase in the conductivity of the material is due to the increase in the conductivity of C-dandling in the PDC-SiOCN materials. 


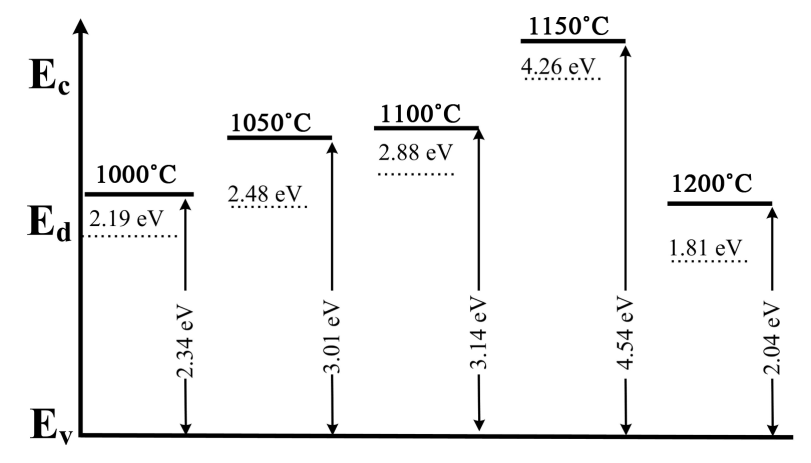

Figure 7. Schematic showing the electronic structures of the PDC-SiOCN as a function of the pyrolysis temperature.

\section{Acknowledgements}

Financial support from the Natural Science Foundation of China (51175444, 61274120), the Fundamental Research Funds for the Central Universities (Xiamen University, 2011121002), the Aviation Science Foundation of China (2013ZD68009), New Century Excellent Talents in Fujian Province University (2013), the Natural Science Foundation of Fujian Province of China (2014J01206), Xiamen Municipal Bureau of Science and Technology (3502Z20143009), and Shenzhen City Science and Technology Innovation Committee (JCYJ20120618155425009) is acknowledged.

\section{References}

[1] Riedel, R., Passing, G., Schönfelde, H. and Brook, R.J. (1992) Synthesis of Dense Silicon-Based Ceramics at Low Temperatures. Nature, 355, 714-717. http://dx.doi.org/10.1038/355714a0

[2] Riedel, R., Kienzle, A., Dressler, W., Ruwisch, L., Bill, J. and Aldinger, F. (1996) A Silicoboron Carbonitride Ceramic Stable to 2,000 Degrees C. Nature, 382, 796-798. http://dx.doi.org/10.1038/382796a0

[3] Wang, Y., Fan, Y., Zhang, L., Zhang, W. and An, L. (2006) Polymer-Derived SiAlCN Ceramics Resist Oxidation at 1400 Degrees C. Scripta Materialia, 55, 295-297. http://dx.doi.org/10.1016/j.scriptamat.2006.05.004

[4] An, L., Wang, Y. and Bharadwai, L. (2004) Silicoaluminum Carbonitride with Anomalously High Resistance to Oxidation and Hot Corrosion. Advanced Engineering Materials, 6, 337-340. http://dx.doi.org/10.1002/adem.200400010

[5] Wang, Y., Fei, W. and An, L. (2006) Oxidation/Corrosion of Polymer-Derived SiAlCN Ceramics in Water Vapor. Journal of the American Ceramic Society, 89, 1079-1082. http://dx.doi.org/10.1111/j.1551-2916.2005.00791.x

[6] Riedel, R., Ruswisch, L.M., An, L. and Raj, R. (1998) Amorphous Silicoboron Carbonitride Ceramic with Very High Viscosity at Temperatures above $1500^{\circ}$ C. Journal of the American Ceramic Society, 81, 3341-3344. http://dx.doi.org/10.1111/j.1151-2916.1998.tb02780.x

[7] An, L., Riedel, R., Konetachny, C., Kleebe, H.J. and Raj, R. (1998) Newtonian Viscosity of Amorphous Silicon Carbonitride at High Temperature. Journal of the American Ceramic Society, 81, 1349-1352. http://dx.doi.org/10.1111/j.1151-2916.1998.tb02489.x

[8] Wang, Y., Zhang, L. and Xu, W. (2008) Effect of Thermal Initiator Concentration on the Electrical Behavior of Polymer-Derived Amorphous Silicon Carbonitrides. Journal of the American Ceramic Society, 91, 3971-3975. http://dx.doi.org/10.1111/j.1551-2916.2008.02782.X

[9] Wang, Y., Ding, J. and Feng W. (2011) Effect of Pyrolysis Temperature on the Piezoresistivity of Polymer-Derived Ceramics. Journal of the American Ceramic Society, 94, 359-362. http://dx.doi.org/10.1111/j.1551-2916.2010.04330.x

[10] Riedel, R., Toma, L. and Janssen, E. (2010) Piezoresistive Effect in SiOC Ceramics for Integrated Pressure Sensors. Journal of the American Ceramic Society, 93, 920-924. http://dx.doi.org/10.1111/j.1551-2916.2009.03496.X

[11] Zhang, L.G., Wang, Y.S., Yun, W., Xu, W.X., Fang, D.J., Zhai, L., Lin, K.C. and An, L.N. (2008) A Silicon Carbonitride Ceramic with Anomalously High Piezoresistivity. Journal of the American Ceramic Society, 91, 1346-1349. http://dx.doi.org/10.1111/j.1551-2916.2008.02275.x

[12] Terauds, K., Sanchez-Jimenez, P.E., Raj, R., Vakifahmetoglu, C. and Colombo, P. (2010) Giant Piezoresistivity of Polymer-Derived Ceramics at High Temperatures. Journal of the European Ceramic Society, 30, 2203-2207. http://dx.doi.org/10.1016/j.jeurceramsoc.2010.02.024

[13] Kroll, P. (2005) Modeling the "Free Carbon” Phase in Amorphous Silicon Oxycarbide. Journal of Non-Crystalline 
Solids, 351, 1121-1126. http://dx.doi.org/10.1016/j.jnoncrysol.2005.01.010

[14] Kroll, P. (2005) Modelling Polymer-Derived Ceramics. Journal of the European Ceramic Society, 25, 163-174. http://dx.doi.org/10.1016/i.jeurceramsoc.2004.07.012

[15] Colombo, P., Mera, G., Riedel, R. and Soraru, G.D. (2010) Polymer-Derived Ceramics: 40 Years of Research and Innovation in Advanced Ceramics. Journal of the American Ceramic Society, 93, 1805-1837. http://dx.doi.org/10.1111/j.1551-2916.2010.03876.x

[16] Colombo, P., Riedel, R., Sorarù, G.D. and Kleebe, H.J. (2010) Polymer Derived Ceramics: From Nano-Structure to Applications. DEStech Publications, Lancaster.

[17] Nghiem, Q.D., Kim, D. and Kim, D.P. (2007) Synthesis of Inorganic-Organic Diblock Copolymers as a Precursor of Ordered Mesoporous SiCN Ceramic. Advanced Materials, 19, 2351-2354. http://dx.doi.org/10.1002/adma.200602348

[18] Sadezky, A., Muckenhuber, H., Grothe, H., Niessner, R. and Poschl, U. (2005) Raman Microspectroscopy of Soot and Related Carbonaceous Materials: Spectral Analysis and Structural Information. Carbon, 43, 1731-1742. http://dx.doi.org/10.1016/j.carbon.2005.02.018

[19] Ferreira, E.H.M., Moutinho, M.V.O., Stavale, F., Lucchese, M.M., Capaz, R.B., Achete, C.A. and Jorio, A. (2010) Evolution of the Raman Spectra from Single-, Few-, and Many-Layer Graphene with Increasing Disorder. Physical Review B, 82, Article ID: 125429. http://dx.doi.org/10.1103/PhysRevB.82.125429

[20] Ferrari, C. and Robertson, J. (2006) Raman Spectrum of Graphene and Graphene Layers. Physical Review Letters, 97, Article ID: 187401. http://dx.doi.org/10.1103/PhysRevLett.97.187401

[21] Viana, G.A., Lacerda, R.G., Freire Jr., F.L. and Marques, F.C. (2008) ESR Investigation of Graphite-Like Amorphous Carbon Films Revealing Itinerant States as the Ones Responsible for the Signal Original. Journal of Non-Crystalline Solids, 354, 2135-2137. http://dx.doi.org/10.1016/j.jnoncrysol.2007.10.063

[22] Salvetat, J.P., Bonard, J.M., Forro, L., Beuneu, F. and IHuillier, C. (1999) Modification of Multiwall Carbon Nanotubes by Electron Irradiation: An ESR Study. Physical Review B, 59, 5945. http://dx.doi.org/10.1103/PhysRevB.59.5945

[23] Trassl, S., Motz, G., Rossler, E. and Ziegler, G. (2002) Characterization of the Free-Carbon Phase in Precursor-Derived Si-C-N Ceramics: I, Spectroscopic Methods. Journal of the American Ceramic Society, 85, 239-244. http://dx.doi.org/10.1111/j.1151-2916.2002.tb00072.x

[24] Prasad, B.L.V., Sato, H., Enoki, T., Hishiyama, Y., Kaburagi, Y., Rao, A.M., Eklund, P.C., Oshida, K. and Endo, M. (2000) Heat-Treatment Effect on the Nanosized Graphite $\pi$-Electron System during Diamond to Graphite Conversion. Physical Review B, 62, Article ID: 11209. http://dx.doi.org/10.1103/PhysRevB.62.11209

[25] Breton, Y., Verstraete, M., Fleurier, R., Cacciaguerra, T., Charlier, J.C., Thomann, A.L. and Salvetat, J.P. (2004) Anomalous ESR Behavior of Carbon Nanofilaments Grown from Palladium Seeds. Carbon, 42, 1049-1052. http://dx.doi.org/10.1016/j.carbon.2003.12.011

[26] Chen, Y.H., Yang, F.Q. and An, L. (2013) On Electric Conduction of Amorphous Silicon Carbonitride Derived from a Polymeric Precursor. Applied Physics Letters, 102, Article ID: 231902. http://dx.doi.org/10.1063/1.4809825

[27] Corte, F.G.D., Rao, S., Nigro, M.A., Suriano, F. and Summonte, C. (2008) Electro-Optically Induced Absorption in Alpha-Si:H/Alpha-SiCN Waveguiding Multistacks. Optics Express, 16, 7540-7550. http://dx.doi.org/10.1364/OE.16.007540

[28] Wang, Y.S., Jiang, T., Zhang, L.G. and An, L. (2009) Optical Absorption in Polymer-Derived Amorphous Silicon Oxycarbonitrides. Journal of the American Ceramic Society, 92, 3111-3113. http://dx.doi.org/10.1111/j.1551-2916.2009.03333.x

[29] Sadigh, B., Erhart, P., Berg, D.A., Trave, A., Schwegler, E. and Bude, J. (2011) First-Principles Calculations of the Urbach Tail in the Optical Absorption Spectra of Silica Glass. Physical Review Letters, 106, Article ID: 027401. http://dx.doi.org/10.1103/PhysRevLett.106.027401 